\title{
Calculations to Support On-line Neutron Spectrum Adjustment by Measurements with Miniature Fission Chambers in the JSI TRIGA Reactor
}

\author{
Tanja Kaiba, Vladimir Radulović, \\ Gašper Žerovnik and Luka Snoj \\ Reactor Physics Department \\ Jožef Stefan Institute \\ Jamova cesta 19, SI-1000 Ljubljana \\ e-mail:tanja.kaiba@ijs.si
}

\author{
Damien Fourmentel, Loïc Barbot \\ and Christophe Destouches \\ CEA, DEN, DER, \\ Instrumentation, Sensors and Dosimetry Laboratory \\ Cadarache, F-13108 St-Paul-Lez-Durance \\ e-mail:damien.fourmentel@cea.fr
}

\begin{abstract}
Preliminary calculations were performed with the aim to establish optimal experimental conditions for the measurement campaign within the collaboration between the Jožef Stefan Institute (JSI) and Commissariat à l'Énergie Atomique et aux Énergies Alternatives (CEA Cadarache). The goal of the project is to additionally characterize the neutron spectrum inside the JSI TRIGA reactor core with focus on the measurement epi-thermal and fast part of the spectrum. Measurements will be performed with fission chambers containing different fissile materials $\left({ }^{235} \mathrm{U},{ }^{237} \mathrm{~Np}\right.$ and $\left.{ }^{242} \mathrm{Pu}\right)$ covered with thermal neutron filters ( $\mathrm{Cd}$ and $\mathrm{Gd}$ ). The changes in the detected signal and neutron flux spectrum with and without transmission filter were studied. Additional effort was put into evaluation of the effect of the filter geometry (e.g. opening on the top end of the filter) on the detector signal. After the analysis of the scoping calculations it was concluded to position the experiment in the outside core ring inside one of the empty fuel element positions.
\end{abstract}

\section{Introduction}

The power distribution in a nuclear reactor can be monitored by neutron detectors, the signal of which depends on the neutron spectrum. The neutron spectrum is divided into the: thermal, epi-thermal and fast part. The thermal part of the neutron spectrum is approximately following Maxwellian shape around thermal neutron energy $(0.0253 \mathrm{eV})$. The epi-thermal part lies between thermal and fast part and follows approximatelly $1 / E$ dependance, it is followed by the fast part with fission spectrum. To be able to efficiently define and optimize the design of the nuclear instrumentation detectors, it is of great importance to know the neutron spectrum at different positions inside the reactor core as accurately as possible. Within the bilateral collaboration project between the Jožef Stefan Institute (JSI) and the Commissariat à l'Énergie Atomique et aux Énergies Alternatives (CEA Cadarache), an extensive experimental campaign is planned at the JSI TRIGA reactor [1] with the aim to establish an on-line neutron spectrum adjustment method. In the campaign, fission rates will be measured using miniature fission chambers [2] developed at the CEA
Cadarache with different fissile deposits, unfiltered and covered with different neutron filters. It was decided to use ${ }^{235} \mathrm{U},{ }^{242} \mathrm{Pu}$ and ${ }^{237} \mathrm{~Np}$ fission chambers in combination with $\mathrm{Cd}$ and $\mathrm{Gd}$ transmission filters [3], [4]. Fission chambers containing different fissile deposits have different energy sensitivity profiles due to different energy dependences of the fission cross-section. The transmission filters act as thermal neutron absorbers and shift the sensitivities to the epi-thermal and fast parts of the neutron spectrum. From the measured fission rates, the magnitudes of the thermal, epi-thermal and fast components of the neutron spectra will be deduced. In the experimental campaign we will further characterize the neutron fields in the JSI TRIGA reactor, and validate the computational model against measurements. This paper presents the prior support calculations, performed to establish the experimental limitations. The effect of different filter geometries (dimensions, material and presence of openings) on the neutron spectra was evaluated.

\section{Computational model}

Neutron transport calculations using the Monte Carlo neutron transport code MCNP6 [5] were performed with the ENDF/B-VII.1 [6] incident neutron cross section library. A full 3D JSI TRIGA reactor model used in calculations is based on the criticality benchmark model [7] which is thoroughly described in the International Handbook of Evaluated Criticality Safety Benchmark Experiments [8]. Our computational model has been expanded, verified and validated by many experiments for different calculations: the effective multiplication factor $k_{e f f}$ [9], power peaking factors [10], reactor kinetic parameters [11], flux and reaction rate distributions [12], [13], [14], neutron spectra and other reactor parameter calculations. In Figure 1 the visual presentation of the JSI TRIGA Mark II reactor model is shown.

Reaction rates obtained from MCNP calculations were normalized taking into account normalization factor [15]:

$$
C=\frac{P \bar{\nu}}{k_{e f f} \bar{w}_{f}},
$$




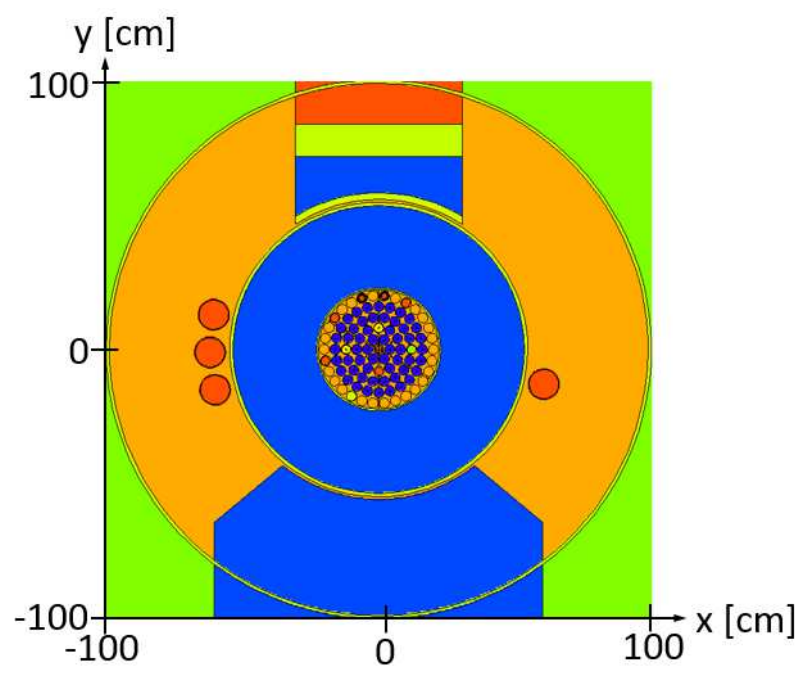

Figure 1. Visual presentation of the JSI TRIGA Mark II MCNP model developed at the JSI Reactor Physics Department.

where $P$ represents reactor power, $k_{e f f}$ stands for effective multiplication factor obtained for individual MCNP simulation, $\bar{\nu}$ represents calculated average number of neutrons produced per fission and $\bar{w}_{f}$ is average energy released per fission contributing to the measurable thermal power (neutrino energy is not taken into account). The $\bar{\nu}$ and $\bar{w}_{f}$ are constants for individual core configuration and were calculated using JSI TRIGA MCNP model with ENDF/BVII.1 nuclear data libraries [6] to be: $\bar{\nu}=2.439$ and $\bar{w}_{f}=$ 193.7 MeV. Normalization was performed for full reactor power $250 \mathrm{~kW}$.

\section{Preliminary design}

The schematic view of the JSI TRIGA reactor core and measuring positions inside the core (red dots) is presented in Figure 2. For all calculations the safety $(\mathrm{S})$ and pulse (P) control rods were completely withdrawn, while the compensating $(\mathrm{C})$ and regulating $(\mathrm{R})$ control rods were in approximately the same position - half withdrawn. In all calculations $\mathrm{R}$ control rod was positioned at step 504 and the $\mathrm{C}$ control rod at step 582, where step 200 indicates a fully withdrawn control rod and step 900 a fully inserted control rod.

In the JSI TRIGA reactor the neutron spectrum is highly thermalized, with approximately $92 \%$ of fissions caused by thermal neutrons, with energies below $0.625 \mathrm{eV}$. The calculated neutron spectra in different measuring positions are presented in Figure 3. We can observe that the total neutron flux is the highest closer to the center of the core (MP5) and decreases towards the edge of the core (MP1). In general the ratio between the thermal and fission part of the neutron spectra increases towards the edge of the core. The detector response depends on the magnitude of the neutron flux and on the shape of the neutron spectrum. If the effect of the neutron spectrum change on the detector

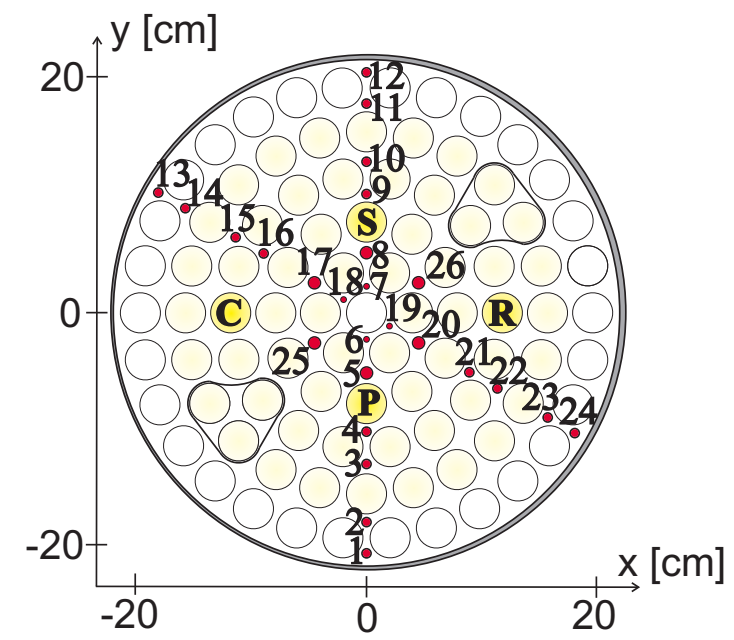

Figure 2. Schematic view of the JSI TRIGA core configuration with fuel elements in light yellow and control rods in dark yellow. Measuring positions are denoted with red dots and numbers.

signal is studied, the effect of the neutron flux change has to be filtered out to achieve accurate evaluation. This can be performed by relative comparison of measurements and calculations performed with and without thermal neutron filters.

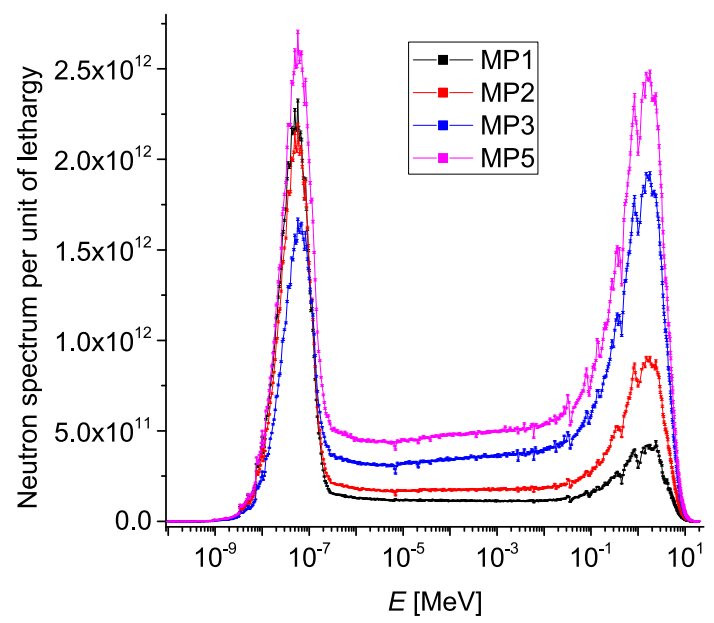

Figure 3. Neutron spectrum per unit of lethargy in different measuring positions inside the reactor core.

In previous research the reactor core has already been characterized with ${ }^{235} \mathrm{U}$ fission chambers, which are highly sensitive to the thermal part of the neutron spectrum [16]. To evaluate the fast and epi-thermal part of the neutron spectrum, fission chambers with fissile coatings with large fission cross section for epi-thermal and fast neutron energies, have to be used. Three different fission chamber coating materials were evaluated to cover different energy regions: ${ }^{235} \mathrm{U},{ }^{237} \mathrm{~Np}$ and ${ }^{242} \mathrm{Pu}$. To minimize the signal due to the thermal neutrons, the fission chambers will be covered with thermal neutron transmission filters. Chosen filter materials are: $\mathrm{Cd}$ and $\mathrm{Gd}$. 
For preliminary calculations transmission filters were modelled as hollow cylinders, without explicitly modelled fission chambers inside, due to the assumed negligible effect on the relative fission rate distribution. The effect of the filter length and configuration on the neutron spectrum inside the filter was studied. To evaluate the effect of the filter length on the detected signal, calculations with single and double filter length were compared. It was assumed that even a small opening inside the filter can result in a high contribution to the detected signal by the thermal part of the neutron spectrum. Therefore configurations with both endings opened and closed were analysed. Different filter configurations are schematically presented in Figure 4 . The chosen thicknesses of transmission filters were: $1.0 \mathrm{~mm}$ for $\mathrm{Cd}$ and $250 \mu \mathrm{m}$ for $\mathrm{Gd}$ with length of $5.5 \mathrm{~cm}$ (single) and $11.0 \mathrm{~cm}$ (double).

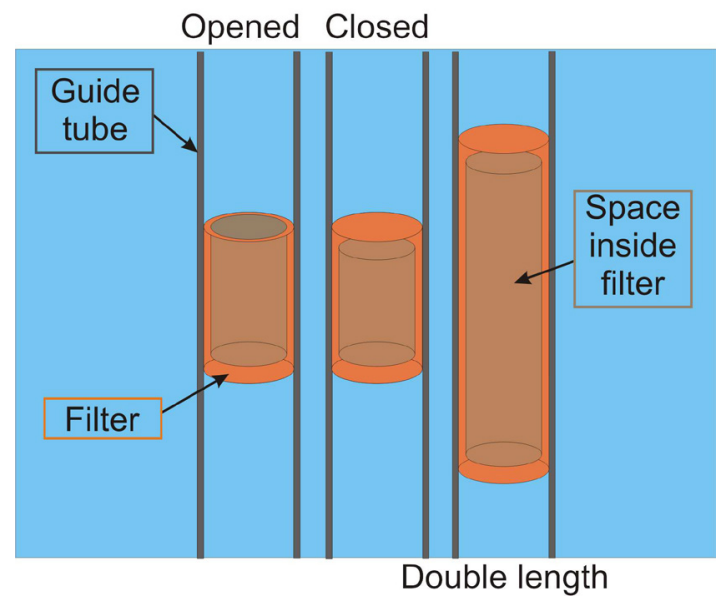

Figure 4. Schematic view of different filter configurations.

\section{Results of preliminary calculations}

The neutron spectrum in MP1 (see Figure 2) for different transmission filter materials and different filter configurations was analysed. In Figure 5 calculated neutron spectra per unit of lethargy are presented through the entire energy range. It can be observed that both filter materials efficiently decrease the thermal neutron part. In Figure 6 a closer view of the thermal and epi-thermal part of the neutron spectrum is presented. The effect of the transmission filter geometry on the neutron spectrum is presented in Figure 7 for the $\mathrm{Cd}$ and in Figure 8 for the Gd filter. It can be observed that the filter length does not affect the neutron spectrum significantly, however the difference is noticeable when it is opened. If the transmission filter is opened, the thermal part of the neutron spectrum becomes non-negligible, especially in case of the Gd filter.

For better understanding of the effect of the transmission filters on the detector response in MP1, the total fission rate $(R)$ over all energy groups for ${ }^{235} \mathrm{U},{ }^{237} \mathrm{~Np}$ and ${ }^{242} \mathrm{Pu}$ was calculated and compared. Results for the fission rates calculated through the entire space inside the filter are

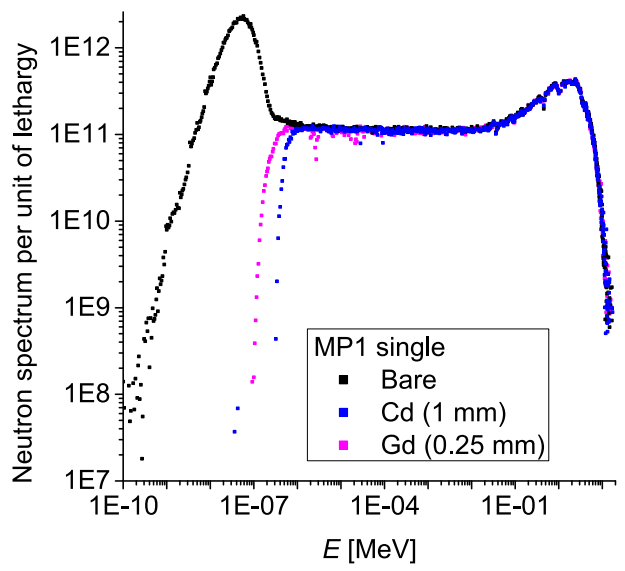

Figure 5. Neutron spectrum per unit of lethargy in MP1 for different thermal neutron filters.

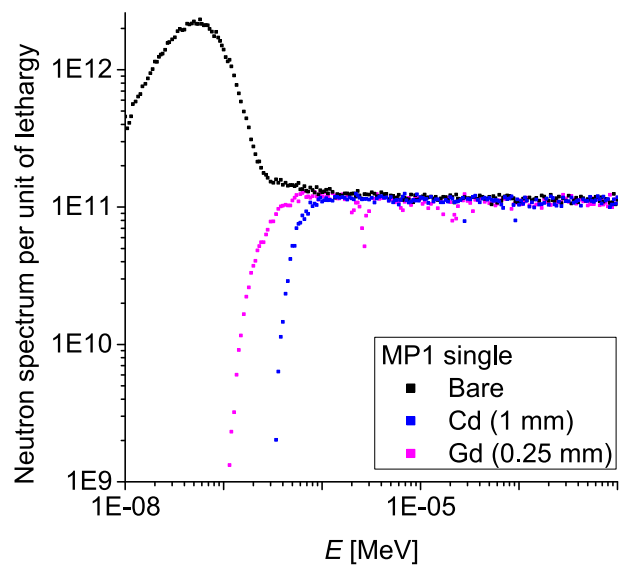

Figure 6. Neutron spectrum per unit of lethargy in MP1 for different thermal neutron filters with closer look at the thermal and epi-thermal part.

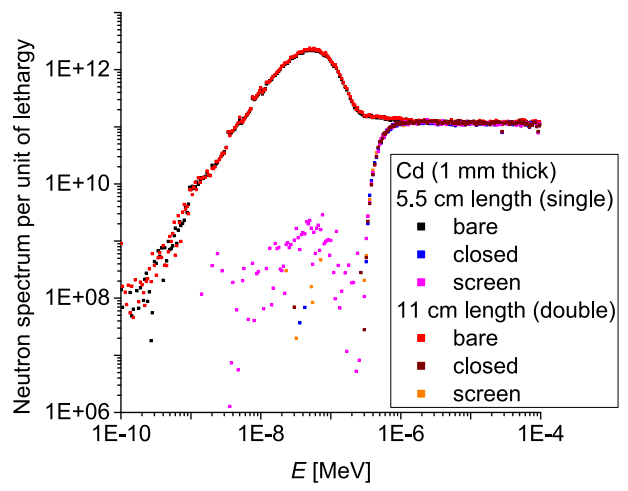

Figure 7. Neutron spectrum per unit of lethargy in MP1 with $1.0 \mathrm{~mm} \mathrm{Cd}$ filter of different geometry.

reported in Tables 1 and 2. As expected, the thermal neutron filter has the largest effect on the fission rate in case of ${ }^{235} \mathrm{U}$. The difference between the open and closed configuration of the filter is expected. Due to the opening inside the filter more thermal neutrons come to the fission chamber 


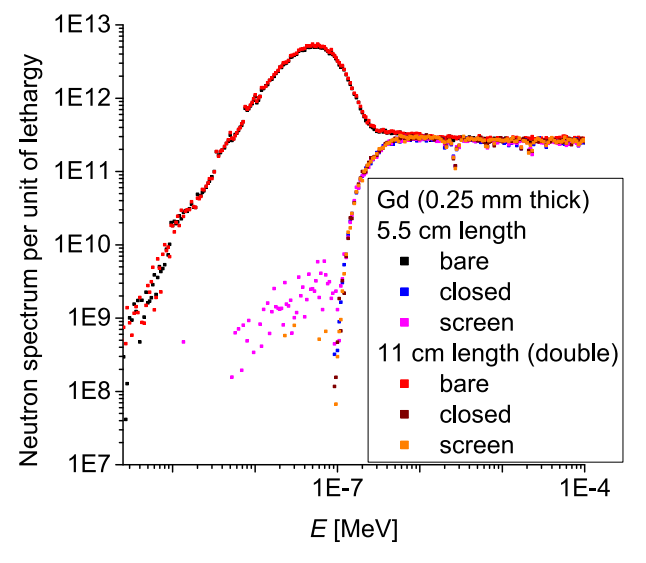

Figure 8. Neutron spectrum per unit of lethargy in MP1 with $250 \mu \mathrm{m} \mathrm{Gd}$ filter of different geometries.

and contribute to the detector signal. For this preliminary comparison, the fission rate through the entire space inside the filter was considered. However, if the fission chambers are positioned at the bottom of the filter a lower thermal neutron contribution to the detected signal is expected. In the comparisons of the fission rates inside single and double length filters, the calculated fission rates were divided by the bare fission rates in order to eliminate the effect of spatial position.

TABLE 1. COMPARISON OF FISSION RATES IN ACTIVE PART OF THE FISSION CHAMBER FOR CD FILTER.

\begin{tabular}{|c|c|c|c|}
\hline $\begin{array}{c}\text { Fissile } \\
\text { material }\end{array}$ & $\begin{array}{c}\text { Filter/Bare }^{(a)} \\
(\text { single, closed) }\end{array}$ & $\begin{array}{c}\text { Single/Double } \\
(\text { closed })\end{array}$ & $\begin{array}{c}\text { Open/Closed } \\
(a) \\
(\text { single })\end{array}$ \\
\hline${ }^{235} \mathrm{U}$ & $0.01490 \pm 0.00004$ & $1.0095 \pm 0.0032$ & $1.5925 \pm 0.0069$ \\
\hline${ }^{237} \mathrm{~Np}$ & $0.9181 \pm 0.0018$ & $1.0194 \pm 0.0018$ & $1.0007 \pm 0.0020$ \\
\hline${ }^{242} \mathrm{Pu}$ & $0.9130 \pm 0.0019$ & $1.0078 \pm 0.0026$ & $1.0024 \pm 0.0021$ \\
\hline \multicolumn{4}{|c|}{ Reported uncertainties are $1 \sigma$ statistical uncertainties. } \\
\hline
\end{tabular}

TABLE 2. COMPARISON OF FISSION RATES IN ACTIVE PART OF THE FISSION CHAMBER FOR GD FILTER.

\begin{tabular}{|c|c|c|c|}
\hline $\begin{array}{c}\text { Fissile } \\
\text { material }\end{array}$ & $\begin{array}{c}\text { Filter/Bare }^{(a)} \\
(\text { single, closed) }\end{array}$ & $\begin{array}{c}\text { Single/Double } \\
(\text { closed })\end{array}$ & $\begin{array}{c}\text { Open/Closed } \\
(\text { single })\end{array}$ \\
\hline${ }^{235} \mathrm{U}$ & $0.02078 \pm 0.00005$ & $1.0078 \pm 0.0024$ & $1.4289 \pm 0.0050$ \\
\hline${ }^{237} \mathrm{~Np}$ & $0.9314 \pm 0.0018$ & $1.0092 \pm 0.0024$ & $1.0007 \pm 0.0020$ \\
\hline${ }^{242} \mathrm{Pu}$ & $0.9271 \pm 0.0018$ & $1.0102 \pm 0.0025$ & $0.9994 \pm 0.0020$ \\
\hline \multicolumn{3}{|c|}{ (a) } & Reported uncertainties are $1 \sigma$ statistical uncertainties. \\
\hline
\end{tabular}

\section{Optimization of irradiation position}

After comparing the multiplication factor $\left(k_{e f f}\right)$ for different configurations, it was confirmed that transmission filters have a high impact on the reactivity. A single $\mathrm{Cd}$ (1.0 $\mathrm{mm}$ thick) or $\mathrm{Gd}(0.6 \mathrm{~mm}$ thick) filter positioned in the Central Channel (center of the reactor core) has approximately $(-500 \pm 4)$ pcm negative reactivity. If the filter is placed in the outside core ring, in one of the empty fuel element positions, its negative reactivity amounts to approximately $(-30 \pm 1) \mathrm{pcm}$. The difference in negative reactivities of the $\mathrm{Cd}$ and $\mathrm{Gd}$ filters is within the statistical uncertainty of the calculations. Therefore, it was concluded that the best option is to place the experiment in one of the empty fuel element positions in the outer ring of the reactor core (F ring).

\section{Conclusion}

Preliminary calculations in support of the experimental campaign, using fission chambers containing different fissile material and covered with thermal neutron transmission filters, were performed. It was determined that the filter geometry can have a large effect on the detector signal, e.g. opening inside the filter can significantly increase the contribution of thermal neutrons (especially in the case of ${ }^{235} \mathrm{U}$ fission chamber). Due to the high negative reactivity of the spectrum filters it was decided to place the experiment in the outside core ring in one of the empty fuel element positions. After analysing preliminary calculations, improved computational design can be made including explicitly modelled fission chambers inside the filters. The experimental campaign is scheduled in autumn 2017. The measured magnitudes of the fission rates of different materials in combination with different transmission filters will be compared to the calculated results. The obtained results will serve as a basis for future research, in which the effect of the control rod movement on the neutron spectrum distribution will be studied.

\section{Acknowledgments}

The research is funded by the bilateral project "Experimental on-line neutron spectra adjustment method using various fission chambers with adequate fission fissile isotopes" between the Ministry of education, science and sport of the Republic of Slovenia and Commissariat à l'énergie atomique et aux énergies alternatives (CEA) under contract number BI-FR/CEA/15-17-005.

\section{References}

[1] Snoj, L., Smodiš, B., 2011. 45 Years of TRIGA Mark II in Slovenia. In: Proceedings of the International Conference Nuclear Energy for New Europe 2011, Bovec, Slovenia, Paper no. 401.

[2] Barbot, L., Domergue, C., Breaud, S., Destouches, C., Villard, J.-F., Snoj, L., Štancar, Ž., Radulović, V., Trkov, A, 2013. Neutron field characterization of irradiation locations applied to the slovenian TRIGA reactor. In: Proceedings of the International Conference Advancements in Nuclear Instrumentation Measurement Methods and their Applications (ANIMMA), 2013, Marseille, France. doi: 10.1109/ANIMMA.2013.6727954.

[3] Filliatre, P., Oriol, L., Jammes, C., Vermeeren, L., 2008. Reasons why Plutonium 242 is the best fission chamber deposit to monitor the fast component of a high neutron flux. Nuclear Instruments And Methods in Physics Research - Section A, 593 (3), pp. 510-518.

[4] Filliatre, L., Oriol, L., Jammes, C., Vermeeren, L., 2009. Joint estimation of the fast and thermal components of a high neutron flux with a two one-line detector system. Nuclear Instruments and Methods in Physics Research - Section A, 603 (3), pp. 415-420. 
[5] Goorley, T., et al., 2012. Initial MCNP 6 Release Overview. LA-UR11-07082, Los Alamos National Laboratory, also Nuclear Technology, 180, pp. 298-315 (Dec 2012).

[6] Chadwick, M.B., et al., 2011. ENDF/B-VII.1 Nuclear Data for Science and Technology: Cross Sections, Covariances, Fission Product Yields and Decay Data. LA-UR 11-05121, Los Alamos National Laboratory, also: Nuclear Data Sheets, 112 Issue 12, pg. 2887-2996 (Dec 2011).

[7] Jeraj, R., Ravnik, M., 1999. TRIGA Mark II Reactor: U(20) Zirconium Hydride Fuel Rods in Water with Graphite Reflector, IEU-COMP-THERM-003, International Handbook of Evaluated Critical Safety Benchmark Experiments, Organization for Economic Cooperation and Development - Nuclear Energy Agency, NEA/NSC/SOC(95)03, Paris, 1999.

[8] ICSBEP, 2009. International Handbook of Evaluated Critical Safety Benchmark Experiments, Organization for Economic Cooperation and Development - Nuclear Energy Agency, NEA/NSC/DOC(95)03, Paris, published on DVD, ISBN 978-92-64-99054-8.

[9] Ravnik, M., Jeraj, R., 2003. Research reactor benchmarks. Nucl. Sci. Eng. 145, 145-152.

[10] Snoj, L., Ravnik, M., 2008. Power peakings in mixed TRIGA cores. Nucl. Eng. Des. 238 (9), 2473-2479.

[11] Snoj, L., Kavčič, A., Žerovnik, G., Ravnik, M., 2010. Calculation of Kinetic Parameters for Mixed TRIGA Cores with Monte Carlo. An Nucl. Ene. 37 (2), 223-229. doi:10.1016/j.anucene.2009.10.020.

[12] Snoj, L., Trkov., A., Jaćimović, R., Rogan, P. Žerovnik, G., Ravnik, M., 2011. Analysis of neutron flux distribution for the validation of computational methods for the optimization of research reactor utilization. Appl. Radiat. Isot. 69, 136-141. doi: 10.1016/j.apradiso.2010.08.019.

[13] Žerovnik, G., Kaiba, T., Radulović, V., Jazbec, A., Rupnik, S. Barbot, L., Fourmentel, D., Snoj, L., 2015. Validation of the neutron and gamma fields in the JSI TRIGA reactor using in-core fission and ionization chambers. Appl. Radiat. Isot. 96, 27-35. doi:10.1016/j.apradiso.2014.10.026.

[14] Štancar, Ž., Snoj, L., Barbot, L., Domergue, C., 2015. Evaluation of Fission Rate Profile Experimental Benchmark at the JSI TRIGA Mark II Reactor Using Monte Carlo Method. In: Proceedings of the Joint International Conference on mathematics and Computation (M\&C), Supercomputing in Nuclear Applications (SNA) and the Monte Carlo (MC) Method, 19-23 April 2015, Tennessee, USA.

[15] Žerovnik, G., Podvratnik, M., Snoj, L., 2014. On normalization of fluxes and reaction rates in MCNP criticality calculations. An. Nucl Ene. 63, 126-128. doi:10.1016/j.anucene.2013.07.045

[16] Kaiba, T., et al., 2017. Evaluation of neutron flux and fission rate distributions inside the JSI TRIGA Mark II reactor using multiple incore fission chambers, submitted to Annals of Nuclear Energy. 